\title{
"Let the Algorithm Do the Work": Reduction of Hypoglycemia Using Sensor-Augmented Pump Therapy with Predictive Insulin Suspension (SmartGuard) in Pediatric Type 1 Diabetes Patients
}

\author{
Torben Biester, MD, Olga Kordonouri, MD, Martin Holder, MD, Kerstin Remus, RN, \\ Dorothee Kieninger-Baum, $\mathrm{MD}^{3}$ Tanja Wadien, $\mathrm{RN}^{2}$, and Thomas Danne, MD ${ }^{1}$
}

\begin{abstract}
Background: A sensor-augmented insulin pump (SAP) using the MiniMed ${ }^{\circledR}$ 640G system with SmartGuard ${ }^{\mathrm{TM}}$ technology allows an automatic stop of insulin delivery based on prediction of low glucose levels. Since pediatric patients are particularly prone to hypoglycemia, this device may offer additional protection beyond conventional sensor-augmented therapy.

Methods: This prospective, pediatric multicenter user evaluation assessed 6 weeks of SAP with SmartGuard (threshold setting for hypoglycemia: $70 \mathrm{mg} / \mathrm{dL}$ ) compared to a preceding period of 2 weeks with SAP only. The primary outcome was the potential reduction in the frequency of hypoglycemic episodes and hypoglycemic intensity (area under the curve [AUC] and time $<70 \mathrm{mg} / \mathrm{dL}$ ).

Results: The study included 24 patients with at least 3 months of insulin pump use (average age: 11.6 \pm 5.1 years, 15 female, average type 1 diabetes duration: $7.5 \pm 4.2$ years, mean \pm SD) who had on average $3.2 \pm 1.0$ predictive suspensions/patient/day. The mean sensor glucose minimum during suspension was $78 \pm 6 \mathrm{mg} / \mathrm{dL}$ and the average suspension time was $155 \pm 47 \mathrm{~min} /$ day. Use of SmartGuard in patients treated as per the protocol $(n=18)$ reduced the number of instances in which the glucose level was $<70 \mathrm{mg} / \mathrm{dL}(1.02 \pm 0.52$ to $0.72 \pm 0.36$; $P=0.027)$, as well as AUC $<70 \mathrm{mg} / \mathrm{dL}(0.76 \pm 0.73$ to $0.38 \pm 0.24 ; P=0.027)$ and the time/day the level fell below $70 \mathrm{mg} / \mathrm{dL}$ ( $73 \pm 56$ to $31 \pm 22 \mathrm{~min}$ ). The reduction of hypoglycemia was not associated with a significant change in mean glucose concentration $(171 \pm 26$ to $180 \pm 19 \mathrm{mg} / \mathrm{dL}, P=0.111)$ and $\mathrm{HbA} 1 \mathrm{c}(7.5 \% \pm 0.5 \%$ to $7.6 \% \pm 0.7 \%,(P=0.329)$. Manual resumption of insulin delivery followed by carbohydrate intake resulted in significantly higher glucose levels $1 \mathrm{~h}$ after suspension compared to SmartGuard suspensions with automatic resume $(190.8 \pm 26.5$ vs. $138.7 \pm 10.3 \mathrm{mg} / \mathrm{dL} ; P<0.001)$.

Conclusions: SmartGuard technology significantly reduced the risk for hypoglycemia in pediatric type 1 diabetes patients without increasing $\mathrm{HbA1c}$. Patients must be educated that when using combining predictive low-glucose insulin suspension technology, extra carbohydrate intake in response to an alarm combined with manual resumption is likely to cause rebound hyperglycemia. The best results were achieved when the user did not interfere with pump operation.
\end{abstract}

Keywords: Sensor-augmented pump therapy (SAP), Continuous glucose monitoring (CGM), Hypoglycemia prevention, Hypoglycemia suspension.

\footnotetext{
${ }^{1}$ AUF DER BULT, Children's Hospital, Hannover, Germany.

${ }^{2}$ Klinikum Stuttgart, Olgahospital, Stuttgart, Germany.

${ }^{3}$ Universitätsmedizin Mainz, Zentrum für Kinder- und Jugendmedizin, Mainz, Germany.

(C) Torben Biester et al., 2017; Published by Mary Ann Liebert, Inc. This Open Access article is distributed under the terms of the Creative Commons Attribution Noncommercial License (http://creativecommons.org/licenses/by-nc/4.0/) which permits any noncommercial use, distribution, and reproduction in any medium, provided the original author(s) and the source are credited.
} 


\section{Introduction}

$\mathbf{H}$ YPOGLYCEMIA IS A significant challenge for patients on insulin therapy, particularly if low glucose levels occur at times when patients cannot respond quickly and/or appropriately. In the Diabetes Control and Complications trial (DCCT), 55\% of severe hypoglycemia events during the night, ${ }^{1}$ and in children, the rates of severe hypoglycemia during sleep were $\geq 75 \% .^{2}$ There is an inverse proportional relationship between severe hypoglycemic events and age, in that, the younger the child, the higher the hypoglycemic risk. ${ }^{3}$ In its most extreme form, severe hypoglycemia can be life-threatening. As such, hypoglycemia is considered to be a cause for "dead in bed syndrome," in which diabetes patients are found dead in the morning after they had been well the day before. ${ }^{4-8}$

Undoubtedly, hypoglycemia represents a burden for the well-being of type 1 diabetes patients and many of these patients suffer from hypoglycemia anxiety. Together with the metabolic effects caused by hormonal counter-regulatory reactions in response to hypoglycemic events, all of these factors contribute to hypoglycemia having a negative impact on glycemic control..$^{9,10}$

Thus, there is a need for a technical solution that can assist with daily therapeutic adjustments of insulin levels. Such adjustments are made possible by combining an insulin pump with a continuous glucose monitoring (CGM) system, which is the basic hardware configuration of a closed loop system. Using the ParadigmVEO ${ }^{\mathrm{TM}}$ System, severe hypoglycemia can be avoided in most cases, and the intensity of even mild hypoglycemic events can be reduced (duration and area under the curve (AUC) in hypoglycemia) in both adult and pediatric patients. ${ }^{11-14}$ Since predictive low alarms are available in with the Medtronic VEO System, a complete avoidance of hypoglycemic events should be possible. However, avoidance of such events is not guaranteed under all everyday circumstances, as sensor values $<55 \mathrm{mg} / \mathrm{dL}(3.1 \mathrm{mmol} / \mathrm{L})$ can be observed on average for $24 \mathrm{~min} /$ day during routine sensor use. ${ }^{15}$ In reality, the protective function of these devices is underutilized in everyday life due to various factors such as alarm fatigue or lack of patient education.

The effectiveness of insulin pumps in preventing hypoglycemia depends on the set threshold. A low threshold setting (e.g., $60 \mathrm{mg} / \mathrm{dL}$ [3.3 mmol/L]) does not allow for complete avoidance of mild hypoglycemia, but higher thresholds (e.g., $80 \mathrm{mg} / \mathrm{dL}$ [4.2 mmol/L]) can. However, higher thresholds can lead to more suspensions, which are each accompanied by an alarm, making alarm fatigue a real possibility. Therefore, avoidance of hypoglycemic conditions through predictive intervention may further reduce hypoglycemia events. This predictive approach has been shown to be superior in in silico modeling studies and exploratory clinical tests that showed reductions in the amount of time that glucose levels were below $70 \mathrm{mg} / \mathrm{dL}$ ( $3.9 \mathrm{mmol} / \mathrm{L})$, even during prolonged exercise. ${ }^{16,17}$ The predictive low-glucose suspension algorithm became commercially available as SmartGuard technology and was implemented as a treatment option available with the MiniMed40G insulin pump (Medtronic).

In this study, we tested the SmartGuard algorithm in a pediatric population, which is known to be particularly prone to hypoglycemia. We examined whether the rate and intensity of hypoglycemia can be lowered using SmartGuard technology, and how insulin delivery suspension affected glycemic control in young type 1 diabetes patients during everyday life.

\section{Patients and Methods}

This was an outpatient, nonrandomized, prospective multicenter observational trial conducted over 2 months at several pediatric hospitals (AUF DER BULT, Hospital for Children and Adolescents, Klinikum Stuttgart, Olgahospital, Children's Department, University Mainz, Center for Children's and Adolescent's medicine). The primary endpoint was the assessment of mean AUC/day in the hypoglycemic area $<70 \mathrm{mg} / \mathrm{dL}(3.9 \mathrm{mmol} / \mathrm{L})$ during sensor-augmented insulin pump (SAP) use with or without SmartGuard technology. The secondary outcome parameters were time spent in hypoglycemia/day (values $<70 \mathrm{mg} / \mathrm{dL}[3.9 \mathrm{mg} / \mathrm{dL}]$ and $\leq 40 \mathrm{mg} / \mathrm{dL}$ $[2.2 \mathrm{mg} / \mathrm{dL}])$. In addition, we examined the effectiveness of the SmartGuard technology with respect to the number of SmartGuard activations per day, the average time of insulin suspension, the lowest glucose levels, and glucose values upon suspension and after resuming insulin delivery.

The study included 24 patients who fulfilled the inclusion criteria of having type 1 diabetes for at least 1 year, were between the ages of 1 to 21 years, and had been using insulin pump therapy (CSII) for at least 3 months.

Exclusion criteria were a known intolerance to a glucose sensor or single sensor components, pregnancy, severe psychic/ psychiatric problems (e.g., eating disorders anorexia, bulimia), drug or alcohol abuse, or inadequate trust in the use of technical parts of the system. After having met all inclusion criteria, the patients and parents were trained in the use of the novel MiniMed 640G System, which has been available on the European market since 2015 .

This prospective study included three consecutive phases: (1) a 4-week prephase for patients to become familiar with the new device (CSII only, no CGM) that served as a MiniMed 640G training and dose optimization period; (2) a 2week Phase 1 period using sensor-augmented pump therapy (SAP: CSII and CGM) without activating either the SmartGuard insulin suspension or the low-glucose suspend (LGS) features. During Phase 1, the alert level for hypoglycemia was set to $70 \mathrm{mg} / \mathrm{dL}$ (3.9 mmol/L); and (3) a 6-week Phase 2 period during which patients used SAP therapy with SmartGuard technology (SAP+ SmartGuard). During Phase 2, the threshold for "suspend before low" was set to $70 \mathrm{mg} / \mathrm{dL}$ (3.9 mmol/L) and the "alert before low" alarm was silenced. The hypoglycemia alert was set to $70 \mathrm{mg} / \mathrm{dL}(3.9 \mathrm{mmol} / \mathrm{L})$ such that the patient received an alert when the set threshold was crossed, even though insulin delivery had already been suspended.

Before starting this phase, the participants and families received special education in the use of SmartGuard technology. Two weeks after starting Phase I, study patients received a telephone call to address potential queries and document possible issues.

After each phase of the study, all data from the pumps were downloaded to the CareLink ${ }^{\mathrm{TM}}$ therapy management software. The evaluation of results was done based on continuous recording of glucose profiles from the CGM component of the MiniMed 640G system. The primary outcome was the mean AUC/day in hypoglycemic area $<70 \mathrm{mg} / \mathrm{dL}(3.9 \mathrm{mmol} /$ $\mathrm{L})$ in both phases in the population treated as per the protocol. 
Table 1. Patient's Characteristics (Baseline, $N=24,15$ Female)

\begin{tabular}{lcc}
\hline Parameter & $\begin{array}{c}\text { Mean } \pm \text { standard } \\
\text { deviation }\end{array}$ & Range \\
\hline Age (years) & $11.7 \pm 5.1$ & $3-17$ \\
Duration of diabetes (years) & $7.2 \pm 4.2$ & $1-14$ \\
Experience in CSII (years) & $5.9 \pm 4.4$ & $1.2-14.7$ \\
Experience in CGM (years) & $0.8 \pm 2.0$ & $0-4.2$ \\
Height $(\mathrm{m})$ & $1.48 \pm 0.27$ & $1.00-1.81$ \\
Weight $(\mathrm{kg})$ & $44.5 \pm 18.1$ & $15.5-68.0$ \\
BMI $\left(\mathrm{kg} / \mathrm{m}^{2}\right)$ & $19.2 \pm 2.5$ & $14.8-25.3$ \\
\hline
\end{tabular}

CGM, continuous glucose monitoring; CSII, insulin pump therapy.

Additional analyses included the time spent in hypoglyce$\mathrm{mia} /$ day, rate of hypoglycemia with values $\leq 70$ and $\leq 40 \mathrm{mg}$ / $\mathrm{dL}$, and data concerning algorithm effectiveness (e.g., time in range $(70-180 \mathrm{mg} / \mathrm{dL})$, time in low range $(<70 \mathrm{mg} / \mathrm{dL})$, time in high range $(>180 \mathrm{mg} / \mathrm{dL})$, number of activations, mean duration of suspension until resumption of insulin delivery, lowest glucose value, and glucose values after resume). Statistical data were assessed with a two-sided $t$-test.

\section{SmartGuard}

The MiniMed 640G SAP system may suspend insulin delivery for at least $30 \mathrm{~min}$ and up to $120 \mathrm{~min}$. Several conditions must be present for SmartGuard activation. If the predicted glucose level drops below $20 \mathrm{mg} / \mathrm{dL}(1.1 \mathrm{mmol} / \mathrm{L})$ above the preset low limit within the next $30 \mathrm{~min}$, insulin infusion is stopped. Automatic resumption occurs only if the glucose value rises at least $20 \mathrm{mg} / \mathrm{dL}(1.1 \mathrm{mmol} / \mathrm{L})$ above the preset low limit and the prediction is at least $40 \mathrm{mg} / \mathrm{dL}$ $(2.2 \mathrm{mmol} / \mathrm{L})$ above the low threshold within $30 \mathrm{~min}$. Insulin delivery is resumed automatically if the predicted value,
$30 \mathrm{~min}$ (minimum suspension time), in the future is more than $20 \mathrm{mg} / \mathrm{dL}$ above the "threshold low" and more than $30 \mathrm{~min}$ since the start of the suspension, or if the maximum $120 \mathrm{~min}$ suspension is exceeded. Patients can also resume insulin delivery manually at any time.

\section{Results}

This study included 24 patients being treated at three pediatric diabetes centers that are experienced in the use of CSII, CGM, and SAP. A comparison of the phases with and without SmartGuard was possible for 18 of the 24 patients, since 5 patients accidentally activated the LGS function with a fixed threshold of $70 \mathrm{mg} / \mathrm{dL}$ during Phase 1. Although data for all patients were used to describe SmartGuard function during Phase 2, these 6 patients were excluded from investigations on the effect of SmartGuard during Phase 1 and Phase 2, thus resulting in a protocol population of 18 patients. Data from the other six patients were analyzed separately to compare the LGS (MiniMed VEO ${ }^{\mathrm{TM}}$ ) and the SmartGuard algorithm. The baseline demographic data for study participants are shown in Table 1 . Two out of the 24 patients were younger than 6 years, 4 were between 6 and 9 years, and the other 18 were between 10 and 18 years of age.

The primary outcome parameter, AUC in the hypoglycemic area $<70 \mathrm{mg} / \mathrm{dL}$, was lowered from $0.76 \pm 0.73 \mathrm{mg} / \mathrm{dL} \times$ day in SAP use without SmartGuard to $0.38 \pm 0.24 \mathrm{mg} / \mathrm{dL} \times$ day if SmartGuard was activated $(P=0.027)$. Correspondingly, with SmartGuard use, the time spent in low values $<70 \mathrm{mg} / \mathrm{dL}$ was reduced significantly from $73 \pm 56$ to $31 \pm 22 \min (P=0.003)$, and consequently, the hypoglycemia intensity expressed as the mathematic product of AUC and time also decreased (Fig. 1). Moreover, the rate of hypoglycemic events was lowered during SmartGuard use, wherein the number of incidences $<70 \mathrm{mg} / \mathrm{dL}$ was reduced from $1.02 \pm 0.52$ to $0.72 \pm 0.36(P=0.027)$, and those below $40 \mathrm{mg} / \mathrm{dL}$ fell from $0.20 \pm 0.22$ to $0.10 \pm 0.10$
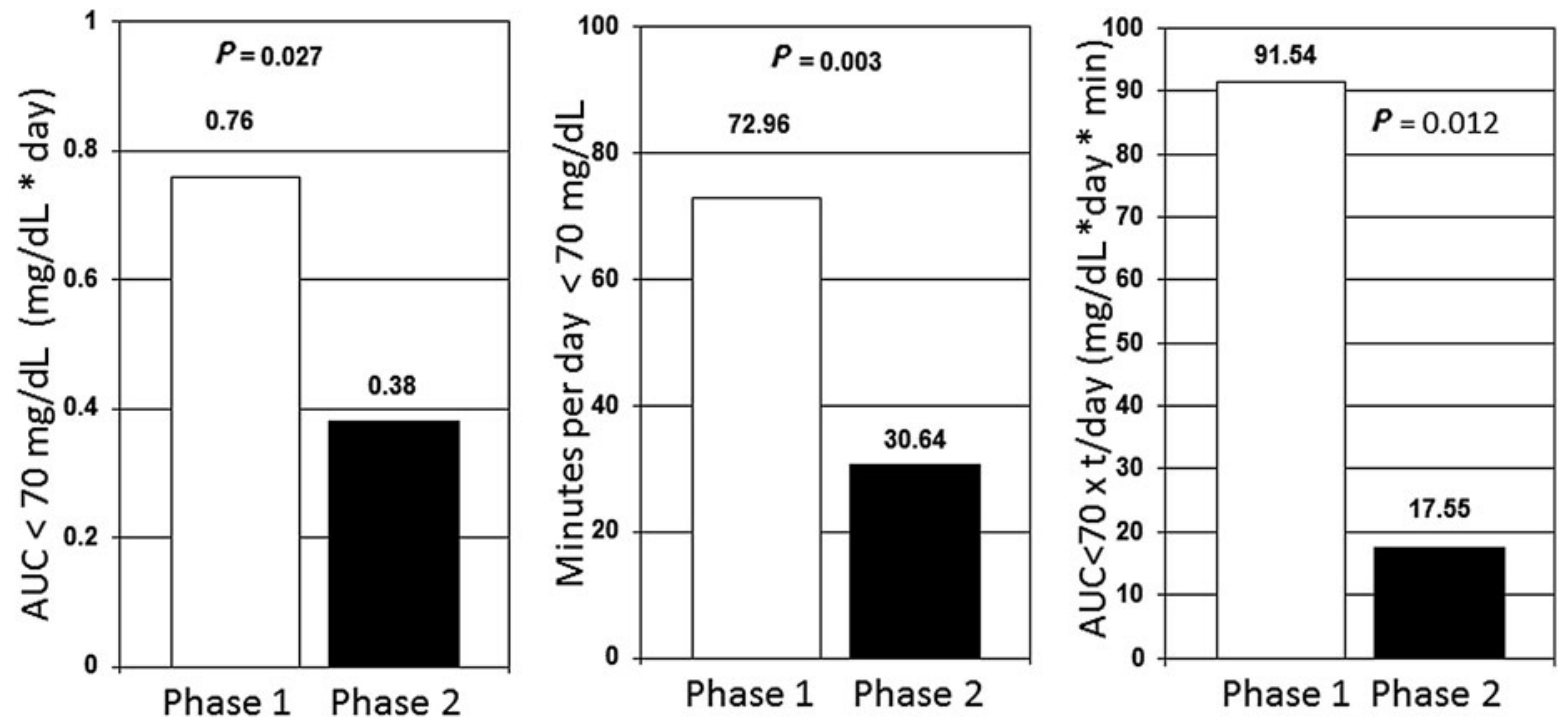

Phase 1 without SmartGuard

Phase 2 with SmartGuard

FIG. 1. Comparison of AUC (left panel) and time in glucose range below $70 \mathrm{mg} / \mathrm{dL}$ (middle panel), as well as intensity of hypoglycemia (right panel) in phases without SmartGuard ${ }^{\circledR}$ (phase 1) and SAP with SmartGuard (phase2). AUC, area under the curve. 
Table 2. Comparison of Glycemic Parameters of Phase 1 (Without SmartGuard) Versus Phase 2 (With SmartGuard)

\begin{tabular}{lccc}
\hline Parameter & Phase 1 & Phase 2 & P (t-test) \\
\hline $\mathrm{HbA}_{1 \mathrm{c}}(\%)$ & $7.48 \pm 0.49$ & $7.55 \pm 0.65$ & 0.329 \\
$\mathrm{HbA}_{1 \mathrm{c}}(\mathrm{mmol} / \mathrm{mol})$ & $58.2 \pm 7.6$ & $59.0 \pm 7.1$ & 0.329 \\
Mean glucose (mg/dL) & $170.6 \pm 26.2$ & $180.17 \pm 19.4$ & 0.111 \\
Standard deviation (mg/dL) & $72.0 \pm 13.8$ & $73.11 \pm 12.8$ & 0.364 \\
Stability index (Mean/SD) & $2.4 \pm 0.3$ & $2.5 \pm 0.3$ & 0.211 \\
AUC $>160 \mathrm{mg} / \mathrm{dL}(\mathrm{mg} / \mathrm{dL} \times$ day) & $35.5 \pm 18.4$ & $40.8 \pm 15.1$ & 0.175 \\
AUC <70 mg/dL (mg/dL $\times$ day) & $0.8 \pm 0.7$ & $0.4 \pm 0.2$ & 0.027 \\
Time <70 mg/dL/day (min) & $73 \pm 56$ & $31 \pm 22$ & 0.003 \\
Excursions <70 mg/dL/day & $1.02 \pm 0.52$ & $0.72 \pm 0.36$ & 0.027 \\
Excursions $\leq 40 \mathrm{mg} / \mathrm{dL} /$ day & $0.20 \pm 0.22$ & $0.10 \pm 0.10$ & 0.038 \\
\hline
\end{tabular}

AUC, area under the curve.

$(P=0.038)$. No severe hypoglycemia requiring external assistance was observed. The significant reduction in hypoglycemia was accompanied by a nonsignificant increase in mean sensor glucose concentration in Phase 2 from $171 \pm 26$ to $180 \pm 19 \mathrm{mg} /$ dL (with SmartGuard) $(P=0.111)$ (Table 2) and a slight increase in $\mathrm{HbA} 1 \mathrm{c}$ from $7.5 \% \pm 0.5 \%(58.2 \pm 7.6 \mathrm{mmol} / \mathrm{mol} \mathrm{Hb})$ to $7.6 \pm 0.7 \%(59.0 \pm 7.1 \mathrm{mmol} / \mathrm{mol} \mathrm{Hb})(P=0.329)$. An analysis of glycemic changes was performed by examining CGM profiles with respect to "Time in Range." A comparison of time spent in high $(>180 \mathrm{mg} / \mathrm{dL})$ and low $(<70 \mathrm{mg} / \mathrm{dL})$ glucose area (time out of range) (Fig. 2) shows that in Phase 2 with SmartGuard, the time in the low range was reduced for each patient, whereas the time above the range was incrementally increased. Time in Range (70-180 mg/dL) was almost the same during Phase 2 (SAP $793 \pm 177 \mathrm{~min} ; 55.1 \%$ vs. SmartGuard ${ }^{\circledR}$ $794 \pm 175 \mathrm{~min} ; 54.9 \% ; P=0.981)$. The Time in Low Range was reduced by the same amount (SAP $93 \pm 73 \mathrm{~min} ; 6.4 \%$ vs.
SmartGuard $41 \pm 20 \mathrm{~min} ; 2,8 \% ; P=0.098)$, and the Time in the High Range was increased (SAP 554 213 min; 38.5\% vs. SmartGuard $612 \pm 175 \mathrm{~min} ; 42,3 \% ; P=0.187$ ).

In Phase 2, the cumulative time in hypoglycemia was $155 \pm 47 \mathrm{~min}$ per day with a mean duration of suspension of $59 \pm 7 \mathrm{~min} /$ day. On average, the minimum glucose value during suspension was $85 \pm 14 \mathrm{mg} / \mathrm{dL}$. In $23.2 \%$ of all cases, glucose values dropped below $70 \mathrm{mg} / \mathrm{dL}$ after SmartGuard activation ("low threshold" in this study). Consequently, hypoglycemic values were prevented in $76.8 \%$ of instances of low glucose, and only $6.5 \%$ of all cases had values that fell below $55 \mathrm{mg} / \mathrm{dL}$.

Insulin delivery suspension and resumption occurred at comparable glucose levels between 90 and $110 \mathrm{mg} / \mathrm{dL}$ (5.0 and $6.1 \mathrm{mmol} / \mathrm{L})$. The minimum glucose values after suspension were usually between 70 and $90 \mathrm{mg} / \mathrm{dL}$ (3.9-5.0 mmol/L). One hour after an automatic resumption (without consecutive

\section{Phase 1 without SmartGuard}

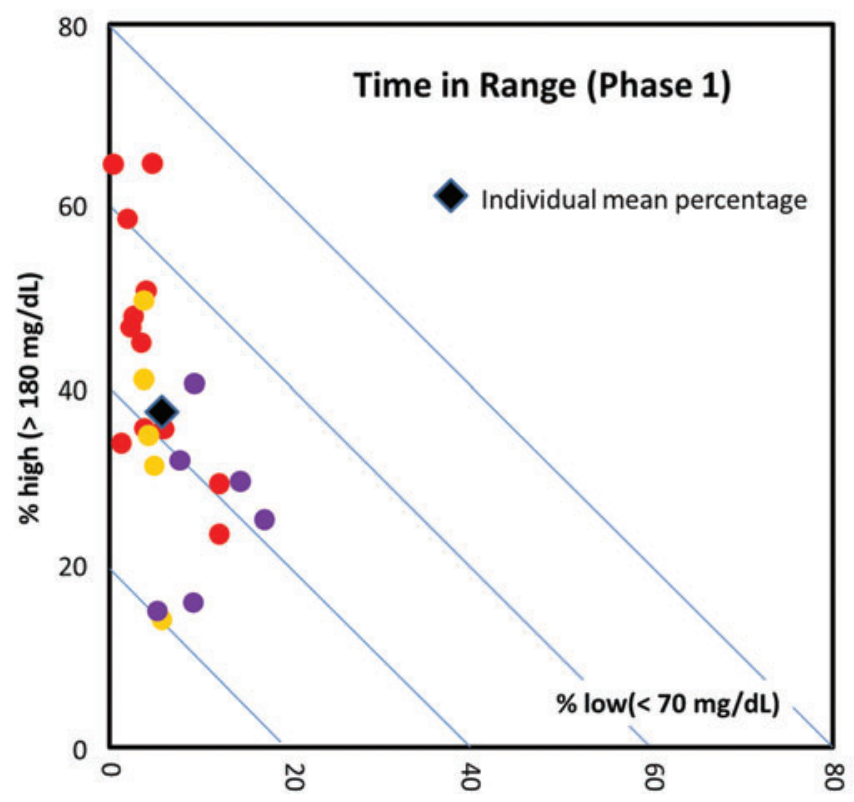

\section{Phase 2 with SmartGuard}

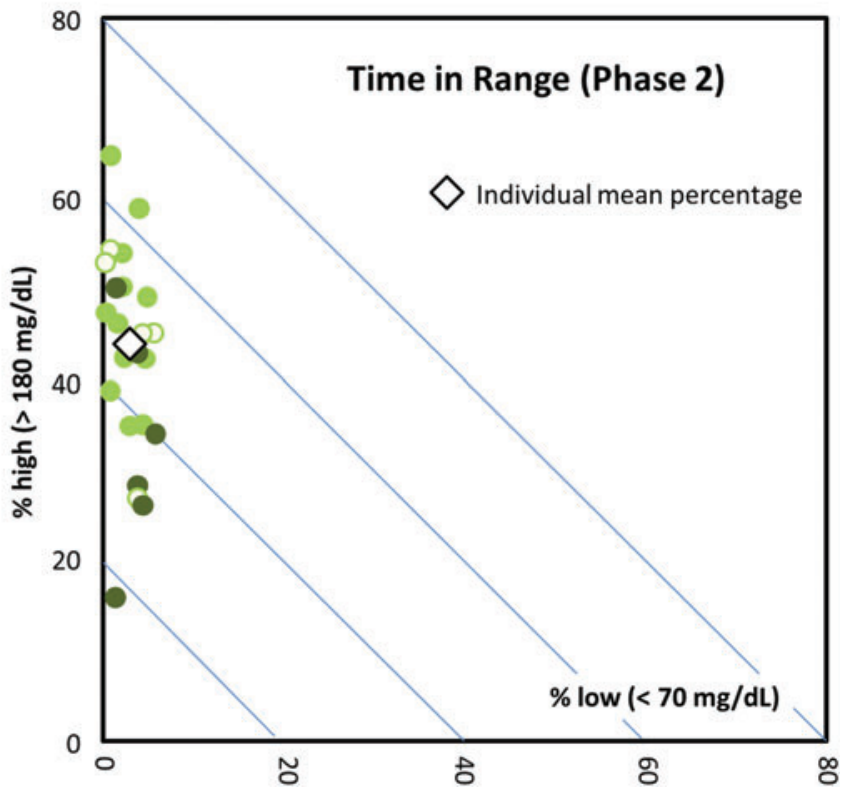

FIG. 2. Corresponding mean values for time in range for individual patients relating percent of time within low glucose (x-axis) and high (y-axis) glucose levels, respectively. 


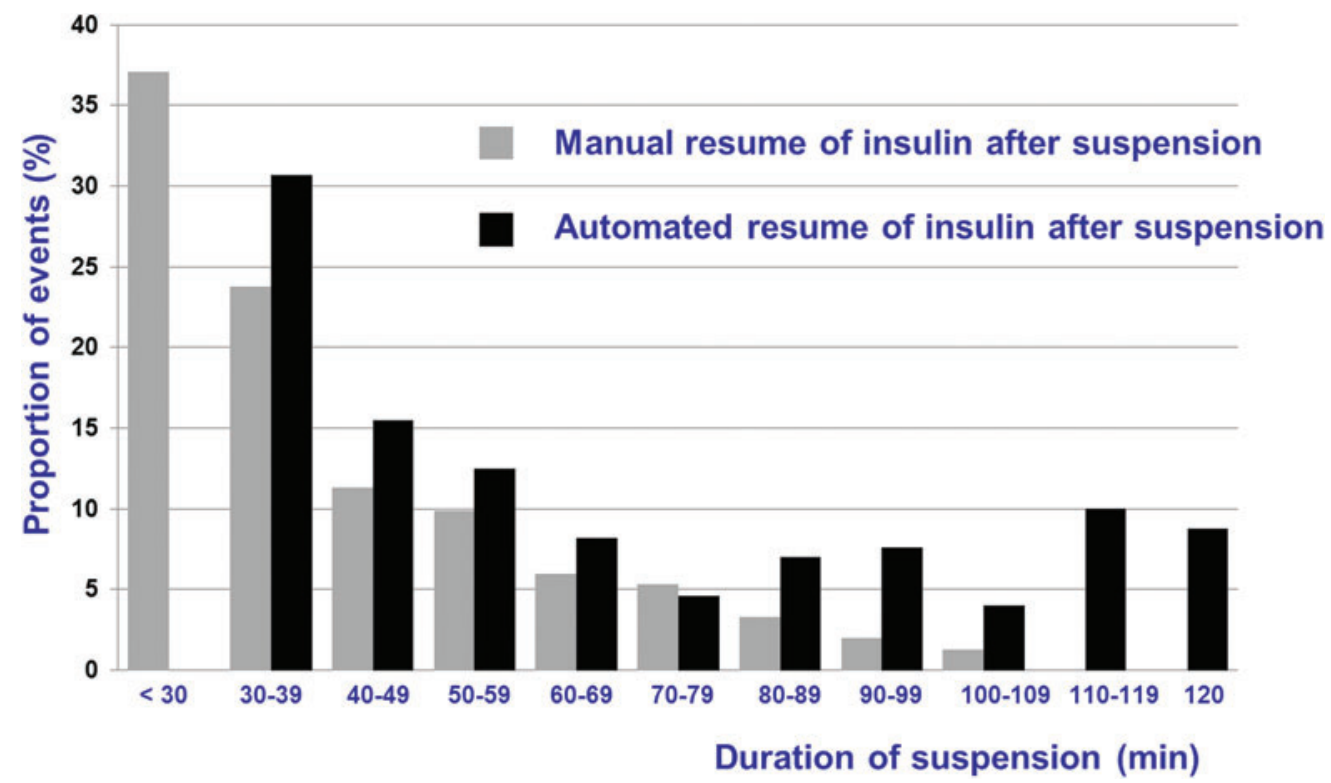

FIG. 3. Percentage of insulin suspension events related to length in suspension and mode of resumption (automatic or manually).

carbohydrate intake), the average glucose level was 30$40 \mathrm{mg} / \mathrm{dL}$ higher, but no rebound hyperglycemia occurred.

An analysis of suspensions by the SmartGuard algorithm in all 24 patients in Phase 2 showed on average $3.1 \pm 1.0$ activations per day. The distribution of the suspension time intervals with respect to the time between automatic suspension and manual resumption showed that for $45.9 \%$ of all suspensions, delivery was resumed manually (usually within $30 \mathrm{~min}$ ) after SmartGuard initiated the suspension (Fig. 3). Although the mean glucose values at suspension $(105 \pm 8 \mathrm{mg}$ / $\mathrm{dL})$ and resumption $(103 \pm 11 \mathrm{mg} / \mathrm{dL})$ of insulin delivery were almost equal, values $1 \mathrm{~h}$ after resumption showed higher average glucose values of $162.0 \pm 15.1 \mathrm{mg} / \mathrm{dL}$. Analysis of potential factors that could influence this increase revealed that the increase depended largely on the patient's management. For example, when patients consumed carbohydrates in addition to insulin suspension to relieve hypoglycemia and if insulin suspension was resumed manually before the automatic start of insulin delivery would have occurred, glucose levels were elevated.

This trend can also be seen in a separate analysis comparing SmartGuard events during the day (08:00 until 22:00) and night (22:00 until 08:00), and whether or not additional carbohydrates $(\mathrm{CHO})$ were consumed (Table 3 and schematically Fig. 4). Although similar glucose concentrations at suspension and resumption were seen, the minimum glucose levels and suspension duration showed substantial differences $1 \mathrm{~h}$ after resumption when patients ate carbohydrates $(190.8 \pm 26.5 \mathrm{mg} / \mathrm{dL}$ vs. $138.7 \pm 10.3 \mathrm{mg} / \mathrm{dL} ; P<0.001$ without $\mathrm{CHO}$ intake). This outcome was further supported by a comparison of glucose values during the day $(174.4 \pm 17.7 \mathrm{mg} / \mathrm{dL})$ versus night $(137.3 \pm 13.8 \mathrm{mg} / \mathrm{dL} ; P<0.001)$, as patients normally consume fewer carbohydrates at night and are less likely to interfere with the predictive low glucose algorithm during sleep.

For the five patients who were not treated according to the protocol and had the fixed threshold suspension (LGS) feature activated during Phase 1, an exploratory analysis showed that SmartGuard was also superior to LGS. This benefit was apparent both for the actual time in hypoglycemia $(\leq 70 \mathrm{mg} / \mathrm{dL})$ as well as the hypoglycemia intensity (AUC $\times$ time $\leq 70 \mathrm{mg} / \mathrm{dL}$ ) (Table 4). However, this benefit was realized at the expense of a small, but not significant rise of mean glucose levels of $\sim 10 \mathrm{mg} / \mathrm{dL}$ (Table 2).

Table 3. Mean Values Before, During, and After Activation of SmartGuard

\begin{tabular}{|c|c|c|c|c|c|}
\hline & $\begin{array}{l}\text { Glucose value } \\
\text { at begin } \\
\text { of insulin } \\
\text { suspension } \\
\text { (mg/dL) }\end{array}$ & $\begin{array}{l}\text { Glucose value } \\
\text { at resume } \\
\text { of insulin } \\
\text { infusion } \\
\text { (mg/dL) }\end{array}$ & $\begin{array}{l}\text { Minimal } \\
\text { Glucose } \\
\text { value during } \\
\text { suspension } \\
\text { (mg/dL) }\end{array}$ & $\begin{array}{c}\text { Glucose value } \\
1 \mathrm{~h} \text { after } \\
\text { resume } \\
\text { of insulin } \\
\text { infusion }(\mathrm{mg} / \mathrm{dL})\end{array}$ & $\begin{array}{l}\text { Time of } \\
\text { suspension } \\
\text { (min) }\end{array}$ \\
\hline $24 \mathrm{~h}$ (all) & $105.0 \pm 7.5$ & $103.4 \pm 11.1$ & $85.1 \pm 13.8$ & $162.0 \pm 15.1$ & $58.8 \pm 7.1$ \\
\hline During day (08 am-10 pm) & $105.6 \pm 8.7$ & $104.3 \pm 10.4$ & $84.3 \pm 15.0$ & $174.4 \pm 17.7$ & $54.1 \pm 8.1$ \\
\hline During night (10 pm-08 am) & $102.4 \pm 5.4$ & $101.4 \pm 12.1$ & $87.4 \pm 12.0$ & $137.3 \pm 13.8$ & $67.9 \pm 13.1$ \\
\hline Without meal during/after suspension & $106.6 \pm 3.6$ & $104.0 \pm 10.7$ & $83.4 \pm 8.5$ & $138.7 \pm 10.3$ & $66.3 \pm 8.2$ \\
\hline With meal during/after suspension & $109.5 \pm 3.0$ & $109.5 \pm 3.0$ & $81.0 \pm 10.6$ & $190.8 \pm 26.5$ & $50.7 \pm 11.4$ \\
\hline
\end{tabular}




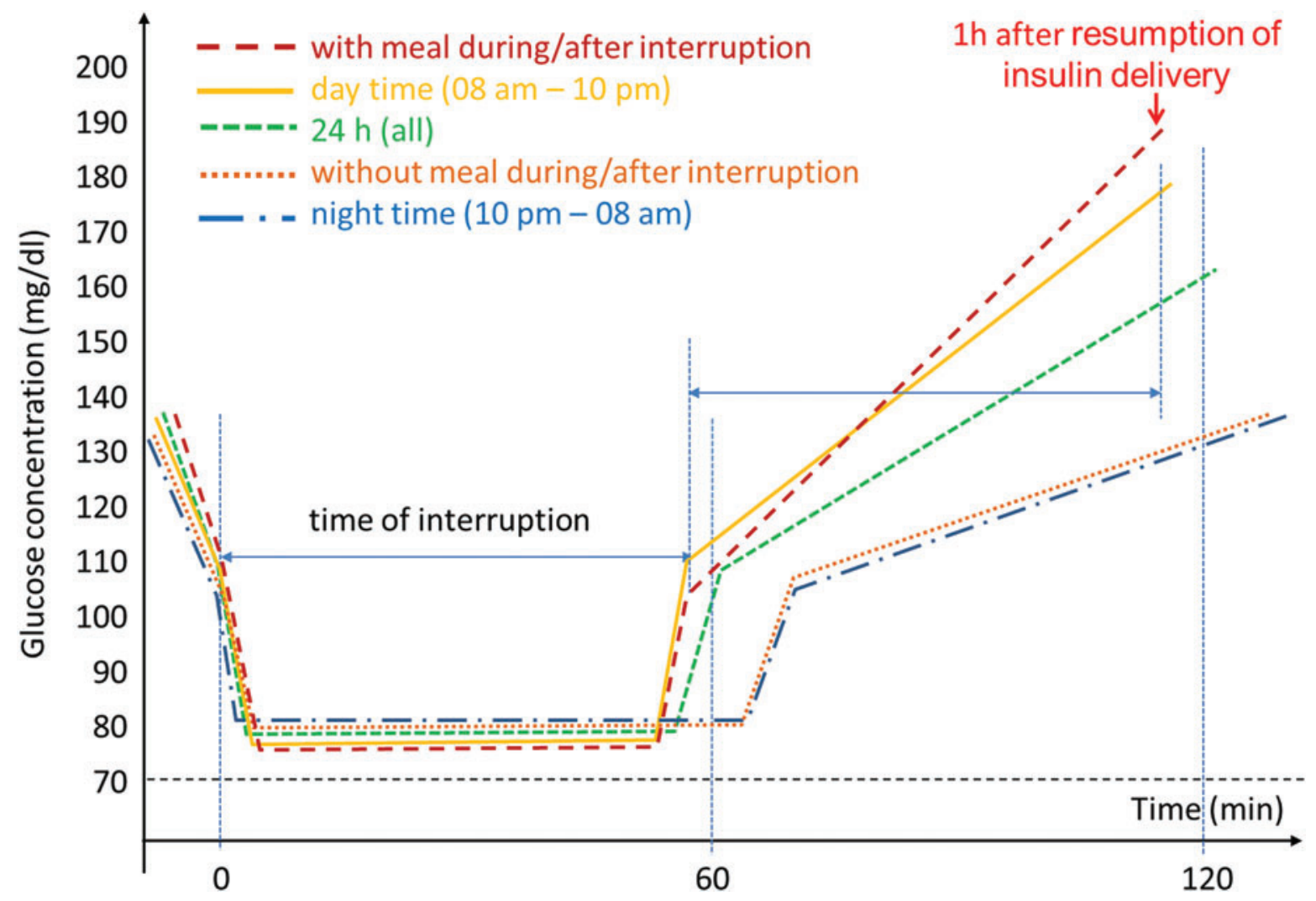

FIG. 4. Schematic view of glucose levels during suspension and values after resumption of insulin infusion related to time of day and $\mathrm{CHO}$ intake.

The distribution of automated and manually terminated suspension events during the course of $24 \mathrm{~h}$ across the 6-week study for a representative patient showed that if the algorithm was allowed to work without patient interference, low glucose levels can be avoided and typical patterns were maintained (Fig. 6).

\section{Discussion}

This pediatric study shows that the predictive low glucose algorithm used by SmartGuard technology is superior to sensor-augmented pump therapy without suspension as used in LGS for the prevention of hypoglycemia in a population known to be prone to low glucose levels. The SmartGuard algorithm, which was optimized by in silico calculation and clinical experiments, ${ }^{16,17}$ is the first commercially available option that can automate a part of daily diabetes management by reducing or preventing hypoglycemia without human in- tervention. Such an automated approach relieves patients of daily decision-making and may prevent problems that arise due to errors in therapy. SmartGuard technology was previously shown to be effective in a 4-week user evaluation of 41 adult patients ${ }^{18}$ and in nighttime home use by youth and adults. ${ }^{19,20}$ However, this study revealed that patient intervention, particularly during the day, which involved premature manual termination of the suspension and a combination of suspension with intake of supplemental oral carbohydrates may result in higher glucose levels $1 \mathrm{~h}$ after the SmartGuard suspension. Thus, the best advice to patients and parents is, as a rule, "let SmartGuard do the work."

With a setting of "suspension before low" at $70 \mathrm{mg} / \mathrm{dL}$, the AUC in the hypoglycemic range was reduced with use of SmartGuard compared to SAP without automation. As mentioned above, this outcome can be attributed not only to the avoidance of hypoglycemia but also could be related to the patient's education on avoidance strategies associated

Table 4. Percentage Reduction of Hypoglycemic Parameters

\begin{tabular}{lccc}
\hline $\begin{array}{l}\text { Hypoglycemia } \\
\text { parameter }\end{array}$ & $\begin{array}{c}\text { SAP+ SmartGuard } \\
\text { vs. SAP without } \\
\text { automation }(18 \text { patients) }\end{array}$ & $\mathrm{P}$ & $\begin{array}{c}\text { SAP+ SmartGuard } \\
\text { vs. SAP+ LGS } \\
\text { (6 patients) }\end{array}$ \\
\hline AUC $<70 \mathrm{mg} / \mathrm{dL}$ & $50.0 \%$ & 0.023 & $30.5 \%$ \\
Time $<70 \mathrm{mg} / \mathrm{d}$ & $57.5 \%$ & 0.003 & $59.6 \%$ \\
\hline
\end{tabular}

LGS, low glucose suspend; SAP, sensor-augmented insulin pump. 


\section{Predictive low glucose insulin suspension events with SmartGuard:Patient 9601 Time of day and duration of suspension}

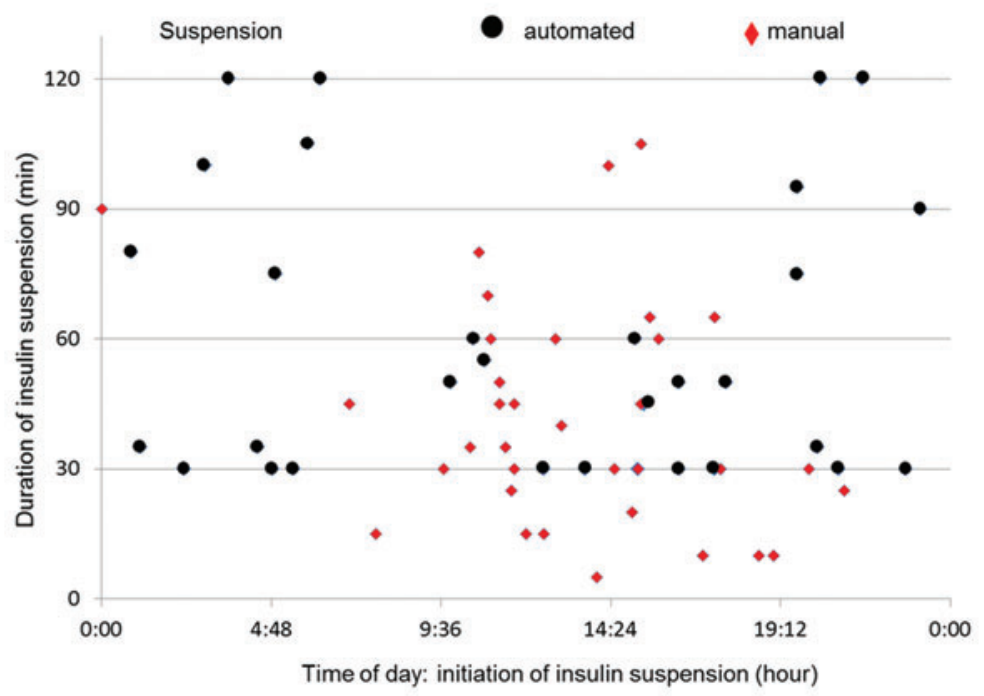

\begin{tabular}{|l|l|}
\hline $\begin{array}{l}\text { duration } \\
\text { (minutes) }\end{array}$ & N \\
\hline $0-29$ & 10 \\
\hline $30-39$ & 22 \\
\hline $40-49$ & 6 \\
\hline $50-59$ & 5 \\
\hline $60-69$ & 7 \\
\hline $70-79$ & 3 \\
\hline $80-89$ & 2 \\
\hline $90-99$ & 2 \\
\hline $100-109$ & 4 \\
\hline $110-119$ & 0 \\
\hline 120 & 4 \\
\hline
\end{tabular}

\begin{tabular}{|c|c|c|c|c|c|c|c|c|c|c|c|c|c|c|c|c|c|c|c|c|c|c|c|c|}
\hline & \multicolumn{24}{|c|}{ Average number of insulin suspension events per hour } \\
\hline $\begin{array}{l}\text { Time } \\
\text { (hours) }\end{array}$ & $\begin{array}{l}0 \\
- \\
1\end{array}$ & $\begin{array}{l}1 \\
- \\
2\end{array}$ & $\begin{array}{l}2 \\
- \\
3\end{array}$ & $\begin{array}{l}3 \\
- \\
4\end{array}$ & $\begin{array}{l}4 \\
- \\
5\end{array}$ & $\begin{array}{l}5 \\
- \\
6\end{array}$ & $\begin{array}{l}6 \\
- \\
7\end{array}$ & $\begin{array}{l}7 \\
- \\
8\end{array}$ & $\begin{array}{l}8 \\
-\end{array}$ & $\begin{array}{l}9 \\
- \\
10\end{array}$ & $\begin{array}{l}10 \\
- \\
11\end{array}$ & $\begin{array}{l}11 \\
- \\
12\end{array}$ & $\begin{array}{l}12 \\
\frac{13}{13}\end{array}$ & $\begin{array}{l}13 \\
- \\
14\end{array}$ & $\begin{array}{l}14 \\
- \\
15\end{array}$ & $\begin{array}{l}15 \\
- \\
16\end{array}$ & $\begin{array}{l}16 \\
- \\
17\end{array}$ & $\begin{array}{l}17 \\
- \\
18\end{array}$ & $\begin{array}{l}18 \\
- \\
19\end{array}$ & $\begin{array}{l}19 \\
- \\
20\end{array}$ & $\begin{array}{l}20 \\
- \\
21\end{array}$ & $\begin{array}{l}21 \\
- \\
22\end{array}$ & $\begin{array}{l}22 \\
- \\
23\end{array}$ & $\begin{array}{l}23 \\
- \\
24\end{array}$ \\
\hline $\begin{array}{l}\text { Events } \\
\text { (n) }\end{array}$ & 2 & 1 & 2 & 1 & 3 & 2 & 1 & 2 & 0 & 2 & 5 & 7 & 4 & 2 & 3 & 9 & 2 & 6 & 1 & 3 & 4 & 2 & 1 & 1 \\
\hline
\end{tabular}

FIG. 5. Representative example of all events of insulin suspension of a study participant during phase 2 with the SmartGuard algorithm in relation to time of day and duration of suspension, and distinguishing if manual (diamonds) or automated (dots) resumption of insulin took place.

with hyperglycemia following automated predictive suspension. No improvement was seen with SmartGuard in terms of average glucose levels. Moreover, the small, although not significant, elevation of mean glucose concentration of $10 \mathrm{mg} / \mathrm{dL}$ (Table 2) may result from heightened patient awareness of hypoglycemia because of sensor use and managing their therapy accordingly.

The suspension time during the day with SmartGuard was on average much shorter, particularly because of frequent manual resumptions (Fig. 5). This result supports the notion that the duration of suspension per se is not related to postsuspension hyperglycemia and is not caused by algorithmdriven insulin management, but instead by patient-related interventions.

Accordingly, education sessions must demonstrate and emphasize that the SmartGuard algorithm is designed to avoid hypoglycemia by initiating insulin suspension predictively and this intervention will happen as a rule when glucose is still in the normoglycemic range, but is trending downwards. Compared to insulin suspension at a threshold level (e.g., LGS of MiniMed VEO, mostly used at or below $70 \mathrm{mg} / \mathrm{dL}$ ), the predictive suspension with SmartGuard leads to more insulin suspension events. In our previous study of LGS using the same study design, we observed an average of 2.6 insulin suspensions per day ${ }^{12}$ compared to a mean of 3.1 insulin suspensions per day in this study. As would be expected from the higher glycemic variability in pediatric patients, this frequency is slightly higher than the 2.1 suspensions per day observed in adults using SmartGuard. ${ }^{18}$ These suspensions were aborted manually in $45.9 \%$ of cases. As such, more time and additional education may be needed for patients and their families to trust the SmartGuard algorithm.

The patients and family members need to understand that a predictive low glucose alarm should not prompt oral carbohydrate intake after suspension, particularly without giving a meal bolus as the patients are used to doing to manage hypoglycemia. Without SmartGuard, this behavior leads to consecutively elevated glucose levels following those events (Tables 3 and 4). In contrast, when there was no patient response to SmartGuard (e.g., during the night), postsuspension glucose levels were in the normal range in that $1 \mathrm{~h}$ after resumption; values were on average $35 \mathrm{mg} / \mathrm{dL}$ above that for the time point at which infusions restarted. (Fig. 4) As expected, postpump suspension hyperglycemia was not seen in another study of a predictive low glucose management system in an in-clinic environment. ${ }^{21}$ Thus, patients should be educated that predictive SmartGuard activation does not take place in the hypoglycemic range and thus no "hypomanagement" is necessary.

The transfer of hypoglycemia management to an automated system may take time and is unfamiliar to patients and especially parents. Despite experience with pumps and CGM, the trust in an automated hypo-management system must be 


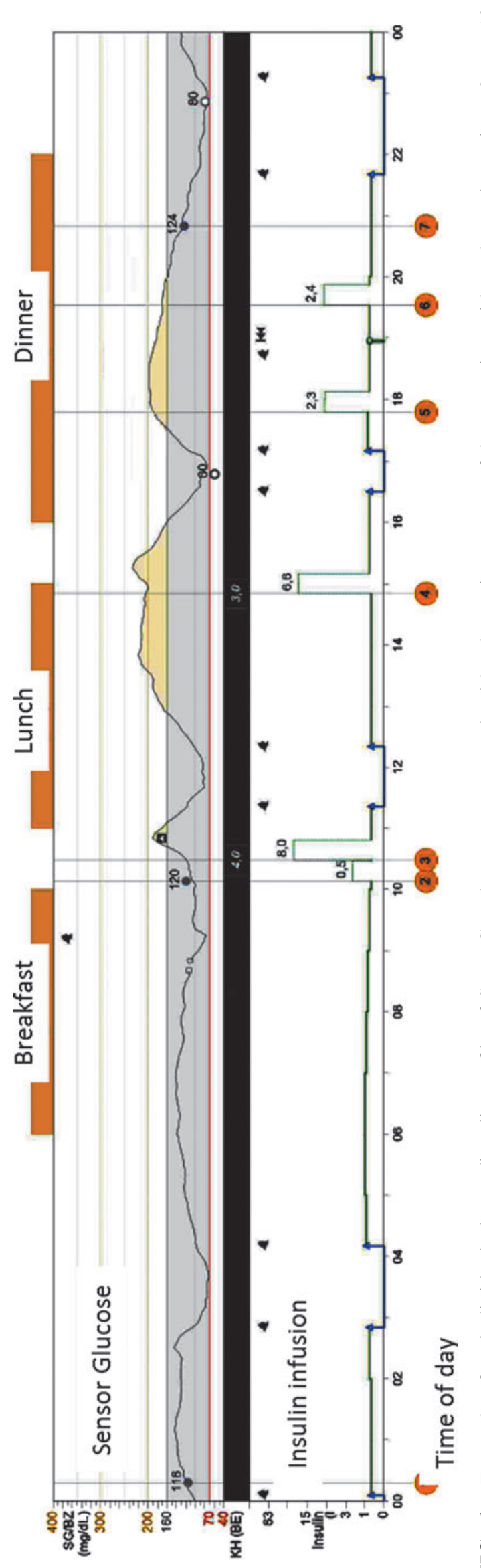

built gradually and could begin with higher glucose limits for suspension.

The potential limitation of the SmartGuard algorithm in preventing hypoglycemia is the amount of active insulin "on board." As the maximum suspension time is $2 \mathrm{~h}$, the maximum insulin dose, which can be compensated by suspension, is the sum of 2-h basal insulin that would have been delivered during the time of interruption. In this study, a consecutive hypoglycemia cannot be prevented entirely by SmartGuard if the insulin bolus delivered before insulin suspension is higher (e.g., by a dosing mistake or a carbohydrate counting error.). This situation may be considered to be a limit of this new technology as it is not a fully automated system such as that seen in a closed-loop approach.

Therefore, if the hypoglycemic range is reached with trend arrows still trending downward in suspension and patients become aware of this trend, relief of hypoglycemia yielded by oral carbohydrate intake followed by resumption of insulin infusion will be necessary to counteract ensuing hypoglycemia.

One of the limitations of this study was the short study time such that sustained effects on metabolic control and HbA1c could not be examined. As this study included only a small group of patients, a pivotal trial of secure prevention of severe hypoglycemia (although no such events were observed in this study) would require a larger patient population and longer study duration. ${ }^{22}$ In addition, studies to examine the function of SmartGuard during intense exercise or sports activities are needed.

The protocol violation of six patients is a weakness of this study and it decreased the number of patients who completed the study as intended. On the other hand, this error provided the opportunity to evaluate the efficacy of SmartGuard compared to the LGS mode in the Paradigm VEO device. Indeed, the new algorithm of predictive suspension was superior in preventing hypoglycemia (Fig. 7).

In conclusion, results from this study are consistent with those from adult studies ${ }^{18}$ and showed that the SmartGuard algorithm built into the MiniMed 640G system can also prevent severe hypoglycemia in children and adolescents. Decreases in both duration of hypoglycemic events and the intensity of hypoglycemia were observed. Furthermore, significantly fewer hypoglycemic events occurred. This result may represent an important step toward the development of a hybrid closed-loop system for insulin delivery. ${ }^{23}$ However, for effective use, patient and families must be counseled to trust the system.

As the algorithm suspends insulin delivery well before the threat of hypoglycemia $(30 \mathrm{~min}$ before reaching a value $20 \mathrm{mg} / \mathrm{dL}$ above the lower limit), a severe hypoglycemia episode is truly unlikely. With such intensive training and education in using the system, patient management leading to consecutive postsuspension elevations in glucose levels by combining manual resumption of insulin with oral $\mathrm{CHO}$ intake should be discouraged unless bolus dosing errors occur immediately before a SmartGuard alert. For these instances, the patients should be encouraged to let the pump do the work.

Concerning severe exercise, more studies are needed to evaluate the impact of SmartGuard to possible hypoglycemia, for example, by sports. 


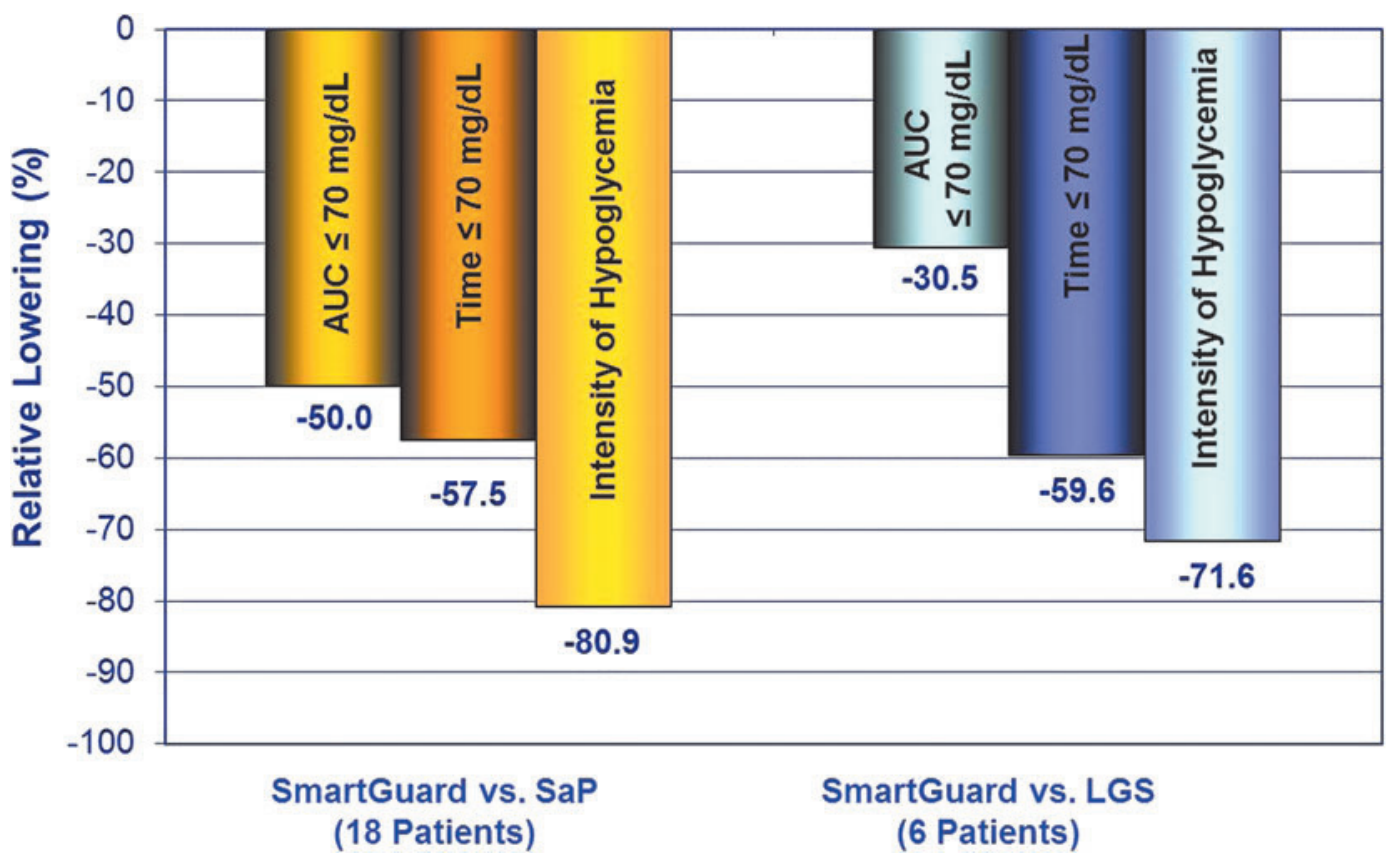

FIG. 7. Compared to both, $640 \mathrm{G}$ algorithm with SmartGuard was superior to SaP and VEO therapy. LGS, low glucose suspend.

Recommendations for patients

- Patients should not become nervous about suspensions in normoglycemia as the device uses a predictive algorithm.

- A glucose threshold of 60 or $70 \mathrm{mg} / \mathrm{dL}$ was shown to be safe for prevention of severe hypoglycemia.

- In case of suspension, patients should monitor the trend and delay hypoglycemia treatment to "let the pump do the work," unless there are severe trends (e.g., two or three arrows down and insulin on board acting).

- If hypoglycemia is treated with carbohydrates, insulin should be resumed immediately to avoid "posthypo peaks."

\section{Source of Funding}

The study is an investigator-initiated trial that received financial support from Medtronic International Trading SarL., Tolochenaz, Switzerland.

\section{Author Disclosure Statement}

The final version of the article was reviewed and approved by the authors. T.B. received speaker honoraria and scientific support from Medtronic. T.D. has received speaker honoraria and research support and has consulted for Abbott, Bayer, BMS/ AstraZeneca, Boehringer Ingelheim, DexCom, Eli Lilly, Medtronic, Novo Nordisk, Sanofi, and Roche. He is a shareholder of DreaMed, Ltd. S.H.J. O.K. has received research support and has consulted for Novo Nordisk and Sanofi. She is a shareholder of DreaMed, Ltd. M.H., D.K.-B., and T.W declare no conflict of interests. K.R. consulted for Medtronic Germany.

\section{References}

1. Epidemiology of severe hypoglycemia in the diabetes control and complications trial: The DCCT Research Group. Am J Med 1991;90:450-459.
2. Davis EA, Keating B, Byrne GC, et al.: Hypoglycemia: incidence and clinical predictors in a large populationbased sample of children and adolescents with IDDM. Diabetes Care 1997;20:22-25.

3. Mortensen HB, Hougaard P: Comparison of metabolic control in a cross-sectional study of 2,873 children and adolescents with IDDM from 18 countries. The Hvidøre Study Group on Childhood Diabetes. Diabetes Care 1997; 20:712-720.

4. Danne T: Different insulin regimes and targets across age groups. Diabet Med 2006;23(Suppl. 4):451-452.

5. Swift PG Tattersall RB, Gill GV: Unexplained deaths of type 1, diabetic patients. Diabet Med 1991;8:49-58.

6. Thordarson H, Sovik O: Dead in bed syndrome in young diabetic patients in Norway. Diabet Med 1995;12:782-787.

7. Sartor G, Dahlquist G: Short-term mortality in childhood onset insulin-dependent diabetes mellitus: a high frequency of unexpected deaths in bed. Diabet Med 1995;12:607-611

8. Gill GV, Woodward A, Casson IF, Weston PJ: Cardiac arrhythmia and nocturnal hypoglycaemia in type 1 diabetes-the 'dead in bed' syndrome revisited. Diabetologia 2009;52:42-45.

9. Cryer PE: Hypoglycaemia: the limiting factor in the glycaemic management of type I and type II diabetes. Diabetologia 2002;45:937-948.

10. Cryer PE, Davis SN, Shamoon H: Hypoglycemia in diabetes. Diabetes Care 2003;26:1902-1912.

11. Choudhary P, Shin J, Wang Y, et al.: Insulin pump therapy with automated insulin suspension in response to hypoglycemia. Diabetes Care 2011;34:2023-2025.

12. Danne T, Kordonouri O, Remus K, et al.: Prevention of hypoglycaemia by using low glucose suspend function in sensor-augmented pump therapy. Diabetes Technol Ther 2011;13:1129-1134.

13. Ly TT, Nicholas JA, Retterath A, et al.: Effect of sensoraugmented insulin pump therapy and automated insulin suspension vs standard insulin pump therapy in patients 
with type 1 diabetes. A Randomized Clinical Trial. JAMA 2013;310:1240-1247.

14. Bergenstal RM, Klonoff DC, Garg SK, et al.; ASPIRE InHome Study Group: Threshold-based insulin-pump interruption for reduction of hypoglycemia. N Engl J Med 2013;369:224-232.

15. Nakamura K, Kent T, Hall T, et al.: Regular-life use of patient RT-CGM Data. Diabetes 2015;64 (Suppl. 1):A243.

16. Zecchin C, Facchinetti A, Sparacino G, et al.: Reduction of number and duration of hypoglycemic events by glucose prediction methods: a proof-of-concept in silico study. Diabetes Technol Ther 2013;15:66-77.

17. Danne T, Tsioli C, Kordonouri O, et al.: The PILGRIM study: In silico modeling of a predictive low glucose management system and feasibility in youth with type 1 diabetes during exercise. Diabetes Technol Ther 2014;16: 338-347.

18. Choudhary P, Olsen BS, Conget I, et al.: Hypoglycemia prevention and user acceptance of an insulin pump system with predictive low glucose management. Diabetes Technol Ther 2016;18:288-291.

19. Calhoun PM, Buckingham BA, Maahs DM, et al.; In Home Closed Loop Study Group: Efficacy of an overnight predictive low-glucose suspend system in relation to hypoglycemia risk factors in youth and adults with type 1 diabetes. J Diabetes Sci Technol 2016;10:12161221.
20. Messer LH, Calhoun P, Buckingham B, et al.; In Home Closed Loop Study Group: In-home nighttime predictive low glucose suspend experience in children and adults with type 1 diabetes. Pediatr Diabetes 2016 [Epub ahead of print]; DOI: 10.1111/pedi.12395.

21. Abraham MB, de Bock M, Paramalingam N, et al.: Prevention of insulin-induced hypoglycemia in type 1 diabetes with predictive low glucose management system. Diabetes Technol Ther 2016;18:436-443.

22. Abraham MB, Nicholas JA, Ly TT, et al.: Safety and efficacy of the predictive low glucose management system in the prevention of hypoglycaemia: protocol for randomised controlled home trial to evaluate the Suspend before low function. BMJ Open 2016;6:e011589.

23. Choudhary P: Implications of predictive low-glucose management system in hybrid of full closed loop system. Diabetes Technol Ther 2016;18:408-409.

Address correspondence to:

Torben Biester, MD

Diabetes Center for Children and Adolescents

AUF DER BULT

Janusz-Korczak-Allee 12

Hannover 30173

Germany

E-mail: biester@hka.de 